Keywords: cancer patients; cancer survivors; menopausal status; moderators; obesity; physical activity; quality of life; resistance training

\title{
Subgroup effects in a randomised trial of different types and doses of exercise during breast cancer chemotherapy
}

\begin{abstract}
K S Courneya ${ }^{*, 1}$, D C McKenzie ${ }^{2}$, J R Mackey ${ }^{3,4}, \mathrm{~K} \mathrm{Gelmon}^{5,6}$, C M Friedenreich ${ }^{7}$, Y Yasui ${ }^{8}$, R D Reid ${ }^{9}$, J R Vallerand ${ }^{1}$, S C Adams ${ }^{1}$, C Proulx ${ }^{10}$, L B Dolan ${ }^{2}$, E Wooding ${ }^{10,11}$ and R J Segal ${ }^{10,11}$

${ }^{1}$ Faculty of Physical Education and Recreation, University of Alberta, Edmonton, AB T6G 2H9, Canada; ${ }^{2}$ School of Kinesiology, University of British Columbia, Victoria, BC V6T 1Z1, Canada; ${ }^{3}$ Department of Oncology, University of Alberta, Edmonton, AB T6G 1Z2, Canada; ${ }^{4}$ Cross Cancer Institute, Edmonton, AB T6G 1Z2, Canada; ${ }^{5}$ Department of Medicine, University of British Columbia, Vancouver, BC V5Z 1M9, Canada; ${ }^{6}$ Department of Medical Oncology, British Columbia Cancer Agency, Vancouver, BC V5Z 4E6, Canada; ${ }^{7}$ Department of Cancer Epidemiology and Prevention Research, Alberta Health Services, Calgary, AB T2S 3C3, Canada; ${ }^{8}$ School of Public Health, University of Alberta, Edmonton, AB T6G 1C9, Canada; ${ }^{9}$ Division of Prevention and Rehabilitation, University of Ottawa Heart Institute, Ottawa, ON K1Y 4W7, Canada; ${ }^{10}$ Department of Medical Oncology, The Ottawa Hospital Cancer Center, Ottawa, ON K1H 8L8, Canada and ${ }^{11}$ Ottawa Hospital Research Institute, Ottawa, ON K1Y 4E9, Canada
\end{abstract}

Background: The Combined Aerobic and Resistance Exercise Trial tested different types and doses of exercise in breast cancer patients receiving chemotherapy. Here, we explore potential moderators of the exercise training responses.

Methods: Breast cancer patients initiating chemotherapy $(N=301)$ were randomly assigned to three times a week, supervised exercise of a standard dose of 25-30 min of aerobic exercise, a higher dose of 50-60 min of aerobic exercise, or a higher dose of 50-60 min of combined aerobic and resistance exercise. Outcomes were patient-reported symptoms and health-related fitness. Moderators were baseline demographic, exercise/fitness, and cancer variables.

Results: Body mass index moderated the effects of the exercise interventions on bodily pain ( $P$ for interaction $=0.038$ ), endocrine symptoms $(P$ for interaction $=0.029)$, taxane/neuropathy symptoms $(P$ for interaction $=0.013)$, aerobic fitness $(P$ for interaction $=0.041)$, muscular strength $(P$ for interaction $=0.007)$, and fat mass $(P$ for interaction $=0.005)$. In general, healthy weight patients responded better to the higher-dose exercise interventions than overweight/obese patients. Menopausal status, age, and baseline fitness moderated the effects on patient-reported symptoms. Premenopausal, younger, and fitter patients achieved greater benefits from the higher-dose exercise interventions.

Conclusions: Healthy weight, fitter, and premenopausal/younger breast cancer patients receiving chemotherapy are more likely to benefit from higher-dose exercise interventions.

Aerobic and resistance exercise improve physical functioning and manage some symptoms in cancer patients (Mishra et al, 2012b) and survivors (Mishra et al, 2012a). Few exercise trials, however, have compared different types or doses of exercise in cancer patients to identify the optimal exercise prescription for a given outcome (Schmitz et al, 2010). Moreover, few exercise trials have formally tested moderators to identify which cancer patients may respond best to a particular exercise intervention (Courneya et al, 2008 , 2009). Such information is critical for understanding what type and dose of exercise might be optimal for improving a particular outcome in a given subset of cancer patients. Here, we report the largest trial to date to examine moderators of the 
exercise response in cancer patients and the first to examine moderators of different types and doses of exercise.

The Combined Aerobic and Resistance Exercise (CARE) Trial compared a three times per week standard dose of 25-30 min of aerobic exercise (STAN) to a higher dose of 50-60 min of aerobic exercise (HIGH) and a higher dose of 50-60 min of combined aerobic and resistance exercise (COMB) in breast cancer patients receiving chemotherapy. We previously reported several positive effects of the higher-dose interventions compared with STAN for physical functioning, endocrine symptoms, bodily pain, and health-related fitness (Courneya et al, 2013). In secondary papers, we also reported that the higher-dose interventions were superior to STAN for managing sleep quality (Courneya et al, 2014c) and depression in patients with clinical levels of depressive symptoms (Courneya et al, 2014a). In this report, we examined clinical moderators of the main outcomes of the CARE trial to determine whether selected subgroups of breast cancer patients responded better or worse to the higher-dose exercise interventions. We included not only several standard demographic and exercise/fitness variables but also key cancer variables that make the field of exercise oncology unique (Courneya, 2014). On the basis of previous results from the CARE Trial (Courneya et al, 2014a,c), we hypothesised that higher physical functioning breast cancer patients (e.g., healthy weight, fitter, younger, previous exercisers, and more tolerable treatments) would respond better to the higher-dose exercise interventions compared with lower physical functioning patients.

\section{MATERIALS AND METHODS}

Setting and participants. The CARE Trial methods have been reported previously (Courneya et al, 2013). The CARE Trial was a multicentre trial with sites in Edmonton, Ottawa, and Vancouver, Canada. Ethics approval was received for each centre and each patient provided informed consent. Eligibility criteria were women $\geqslant 18$ years old with stage I-IIIc breast cancer initiating adjuvant chemotherapy. Women were excluded if they had transabdominal rectus abdominis muscle reconstructive surgery, incomplete axillary surgery, another significant health problem, or were not approved by their treating oncologist. Eligible participants were identified by their treating oncologist in the clinic and recruited by a research coordinator.

Randomisation. After baseline assessments, participants were stratified by centre and chemotherapy regimen (any Herceptin vs no Herceptin/any taxane vs no Herceptin/no taxane) and randomly assigned to STAN, COMB, or $\mathrm{HIGH}$ in a $1: 1: 1$ ratio using a computer-generated program. The allocation sequence was generated in Edmonton and concealed from the project directors at each site who assigned participants to groups.

Exercise training interventions. Details of the exercise training interventions have been described elsewhere (Courneya et al, 2013). Briefly, participants exercised for the duration of their chemotherapy treatment. STAN were prescribed the Physical Activity Guidelines for Americans (United States Department of Health and Human Services, 2008), which have been endorsed for cancer survivors (Schmitz et al, 2010; Rock et al, 2012). The guidelines recommend a minimum of $75 \mathrm{~min}$ of vigorous intensity aerobic exercise spread over at least 3 days per week (i.e., 25-30 min per session). HIGH followed double the minimum guidelines of $150 \mathrm{~min}$ of vigorous intensity aerobic exercise per week (i.e., 50-60 min per session). COMB followed the same aerobic exercise guideline as STAN plus a resistance training programme for 3 days per week that was completed immediately after the aerobic exercise portion (i.e., about 50-60 min of total combined exercise). For each supervised exercise session, exercise trainers recorded the attendance and completion of the exercise prescription.
Selection and assessment of outcomes for the moderator analyses. We examined the main patient-reported outcomes and health-related fitness outcomes from the CARE Trial (Courneya et al, 2013). Patient-reported outcomes were assessed at baseline, twice during chemotherapy, and 3-4 weeks after chemotherapy and consisted of physical functioning and bodily pain assessed by the Medical Outcomes Survey Short Form (SF)-36 (Ware et al, 1995); as well as fatigue symptoms (Yellen et al, 1997), taxane/neuropathy symptoms (Cella et al, 2003), and endocrine symptoms (Fallowfield et al, 1999).

Health-related fitness outcomes were assessed at baseline and post chemotherapy. Aerobic fitness was evaluated using a maximal incremental exercise protocol on a treadmill (Wasserman et al, 1999). Muscular strength was determined by an equation that used 7-10 repetitions of a submaximal weight to estimate maximal strength on the leg press and horizontal bench press (Kraemer et al, 2002). Whole-body fat mass and lean body mass were assessed by dual energy X-ray absorptiometry.

Selection and assessment of moderators. We selected 12 moderators on the basis of their scientific plausibility, clinical utility, distribution in our data set, and support in previous research (Courneya et al, 2008, 2009, 2014a, 2014c). Three moderators were demographic variables consisting of age ( $<50$ years $v s \geqslant 50$ years), marital status (married vs not married), and menopausal status (premenopausal $v s$ postmenopausal). Four moderators were exercise/ fitness variables consisting of meeting aerobic exercise guidelines at baseline (equivalent of $<150 v s \geqslant 150 \mathrm{~min}$ of exercise per week), meeting strength exercise guidelines at baseline $(<$ two $v s \geqslant$ two sessions per week), baseline aerobic fitness $\left(<27.5 v s \geqslant 27.5 \mathrm{ml} \mathrm{kg}^{-1}\right.$ $\left.\min ^{-1}\right)$, and body mass index ( $<25.0$ vs $25.0-29.9 v s \geqslant 30 \mathrm{~kg} \mathrm{~m}^{-2}$ ). Five moderators were cancer variables consisting of disease stage (stages I/IIa vs stages IIb/III), type of surgery (lumpectomy vs mastectomy), anthracycline treatment (no $v s$ yes), taxane treatment (none $v s$ concurrent $v s$ sequential), and length of chemotherapy (12 weeks $v s \geqslant 18$ weeks).

Data analyses. We used repeated-measures analyses of covariance to assess effect modification of the interventions by each hypothesised moderator in the form of an interaction test. We modelled each of the five patient-reported outcomes at the three post-randomisation time points to compare the average mean change over time across intervention-moderator groups (Diggle et al, 2002). We used univariate analyses of covariance for each of the four health-related fitness outcomes that had only one postrandomisation time point. For muscular strength, we report only the upper body strength measure as the interaction results were the same as for the lower body strength measure. Consistent with our main analyses (Courneya et al, 2013), we adjusted for the baseline value of the outcome, age, education, previous exercise, body mass index, disease stage, surgery type, and chemotherapy protocol. For all analyses, we followed the intention-to-treat principle and included all participants with follow-up data. We examined demographic moderators only for patient-reported outcomes because there was limited biologic plausibility for their effect on objective exercise responses. We conducted 96 tests of interactions but did not adjust for multiple comparisons because our trial was not powered to detect interactions and we considered these analyses to be hypothesis generating. Moreover, our approach was to interpret the general pattern of the results rather than any isolated interactions.

\section{RESULTS}

Participant flow through the trial has been reported elsewhere (Courneya et al, 2013). Briefly, we randomised 301 of 728 (41\%) eligible patients and obtained complete patient-reported outcome 
Table 1. Baseline distribution of proposed moderators in the CARE Trial, Canada, 2008-2011

\begin{tabular}{|c|c|c|c|c|}
\hline Variables & Overall $(n=296)$ & Standard $(n=95)$ & High $(n=99)$ & Combined $(n=102)$ \\
\hline \multicolumn{5}{|l|}{ Demographic variables } \\
\hline \multicolumn{5}{|l|}{ Age } \\
\hline$<50$ years & 148 (50.0\%) & $50(52.6 \%)$ & $55(55.6 \%)$ & $43(42.2 \%)$ \\
\hline$\geqslant 50$ years & $148(50.0 \%)$ & $45(47.4 \%)$ & 44 (44.4\%) & $59(57.8 \%)$ \\
\hline \multicolumn{5}{|l|}{ Marital status } \\
\hline Married & $192(64.9 \%)$ & 59 (62.1\%) & $63(63.6 \%)$ & 70 (68.6\%) \\
\hline Not Married & 104 (35.1\%) & $36(37.9 \%)$ & $36(36.4 \%)$ & $32(31.4 \%)$ \\
\hline \multicolumn{5}{|l|}{ Menopausal status } \\
\hline Premenopausal & $182(61.5 \%)$ & $64(67.4 \%)$ & $63(63.6 \%)$ & $55(53.9 \%)$ \\
\hline Postmenopausal & $114(38.5 \%)$ & $31(32.6 \%)$ & $36(36.4 \%)$ & $47(46.1 \%)$ \\
\hline \multicolumn{5}{|l|}{ Exercise/fitness variables } \\
\hline \multicolumn{5}{|l|}{ Baseline aerobic exercise } \\
\hline Not meeting guidelines & 207 (69.9\%) & $66(69.5 \%)$ & 71 (71.7\%) & $70(68.6 \%)$ \\
\hline Meeting guidelines & 89 (31.1\%) & $29(30.5 \%)$ & $28(28.3 \%)$ & $32(31.4 \%)$ \\
\hline \multicolumn{5}{|l|}{ Baseline strength exercise } \\
\hline Not meeting guidelines & 234 (79.1\%) & 75 (78.9\%) & $81(81.8 \%)$ & $78(76.5 \%)$ \\
\hline Meeting guidelines & $62(20.9 \%)$ & $20(21.1 \%)$ & $18(18.2 \%)$ & $24(23.5 \%)$ \\
\hline \multicolumn{5}{|l|}{ Baseline aerobic fitness } \\
\hline$<27.5 \mathrm{ml} \mathrm{kg}^{-1} \mathrm{~min}^{-1}$ & $145(49.0 \%)$ & $43(45.3 \%)$ & $43(43.4 \%)$ & $59(57.8 \%)$ \\
\hline$\geqslant 27.5 \mathrm{ml} \mathrm{kg}^{-1} \mathrm{~min}^{-1}$ & $151(51.0 \%)$ & $52(54.7 \%)$ & $56(56.6 \%)$ & $43(42.2 \%)$ \\
\hline \multicolumn{5}{|l|}{ Body mass index } \\
\hline Healthy weight & $146(49.3 \%)$ & 46 (48.4\%) & 58 (58.6\%) & $42(41.2 \%)$ \\
\hline Overweight & $81(27.4 \%)$ & $33(34.7 \%)$ & $26(26.3 \%)$ & $22(21.6 \%)$ \\
\hline Obese & 69 (23.3\%) & $16(16.8 \%)$ & $15(15.2 \%)$ & $38(37.3 \%)$ \\
\hline \multicolumn{5}{|l|}{ Cancer variables } \\
\hline \multicolumn{5}{|l|}{ Disease stage } \\
\hline I/lla & 203 (68.6\%) & $62(65.3 \%)$ & 70 (70.7\%) & $71(69.6 \%)$ \\
\hline$\|\mathrm{lb} /\| \mathrm{la}$ & 93 (31.4\%) & $33(34.7 \%)$ & $29(29.3 \%)$ & 31 (30.4\%) \\
\hline \multicolumn{5}{|l|}{ Surgical protocol } \\
\hline Lumpectomy & $167(56.4 \%)$ & 47 (49.5\%) & 57 (57.6\%) & $63(61.8 \%)$ \\
\hline Mastectomy & $129(43.6 \%)$ & $48(50.5 \%)$ & 42 (42.4\%) & 39 (38.2\%) \\
\hline \multicolumn{5}{|l|}{ Anthracycline treatment } \\
\hline No anthracyclines & 214 (72.3\%) & $62(65.3 \%)$ & $74(74.7 \%)$ & 78 (76.5\%) \\
\hline Anthracyclines & $82(27.7 \%)$ & $33(34.7 \%)$ & 25 (25.3\%) & $24(23.5 \%)$ \\
\hline \multicolumn{5}{|l|}{ Taxane treatment } \\
\hline No taxane & $28(9.5 \%)$ & 7 (7.4\%) & $11(11.1 \%)$ & $10(9.8 \%)$ \\
\hline Concurrent taxane & 115 (38.9\%) & $40(42.1 \%)$ & $36(36.4 \%)$ & 39 (38.2\%) \\
\hline Sequential taxane & 153 (51.7\%) & $48(50.5 \%)$ & $52(52.5 \%)$ & $53(52.0 \%)$ \\
\hline \multicolumn{5}{|l|}{ Length of chemotherapy } \\
\hline 12 weeks & 89 (31.1\%) & $28(29.5 \%)$ & $28(28.3 \%)$ & $33(32.4 \%)$ \\
\hline$\geqslant 18$ weeks & 207 (69.9\%) & $67(70.5 \%)$ & $71(71.7 \%)$ & 69 (67.6\%) \\
\hline
\end{tabular}

data on $296(98.3 \%)$ patients. The distribution of the proposed moderators is reported in Table 1. Detailed adherence to the exercise interventions is reported elsewhere (Courneya et al, 2013). STAN, HIGH, and COMB attended $88 \%, 82 \%$, and $78 \%$ of their aerobic exercise sessions $(P=0.004)$ with an average duration of 28 $($ s.d. $=4), 48$ (s.d. =8), and 27 (s.d.=3) min, respectively. COMB completed $66 \%(33 / 50)$ of the strength training sessions.

Statistically significant interactions were identified for 13 of the $96(14 \%)$ tests. Note that for many of the outcomes, including aerobic fitness, there was a substantial decline over the course of chemotherapy and the benefit of the higher-dose exercise interventions was to partially blunt these declines. Body mass index moderated the effect of the exercise interventions on bodily pain ( $P$ for interaction $=0.038$; Figure 1a), endocrine symptoms $(P$ for interaction $=0.029$; Figure $1 \mathrm{~b})$, taxane/neuropathy symptoms ( $P$ for interaction $=0.013$; Figure $1 \mathrm{c}$ ), aerobic fitness $(P$ for interaction $=0.041$; Figure $1 \mathrm{~d})$, muscular strength ( $P$ for interaction $=0.007$; Figure $1 \mathrm{e})$, and fat mass $(P$ for interaction $=0.005 ;$ Figure $1 \mathrm{~g})$. Stratified subgroup analyses (Table 2) generally showed that healthy weight patients benefited 

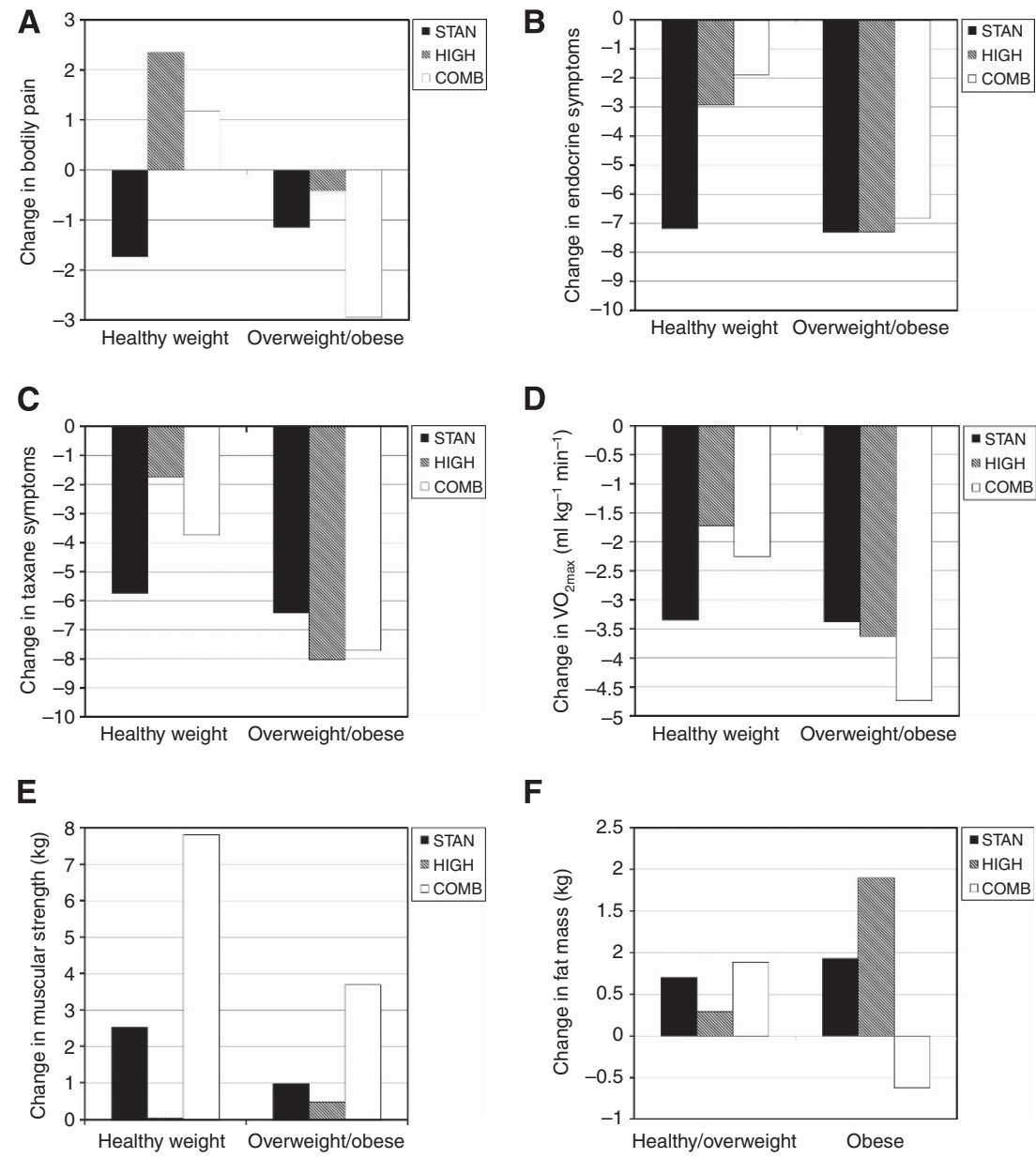

Figure 1. Body mass index as a moderator of exercise effects during breast cancer chemotherapy on (A) bodily pain, (B) endocrine symptoms, (C) taxane symptoms, (D) aerobic fitness, (E) muscular strength, and (F) fat mass. Note: positive change scores (or less negative change scores) are better for all outcomes except fat mass. Abbreviations: $\mathrm{COMB}=$ combined aerobic and resistance exercise; $\mathrm{HIGH}=\mathrm{high}$ volume of aerobic exercise; STAN = standard volume of aerobic exercise.

from the higher-dose exercise interventions more than overweight/ obese patients with one exception; obese patients benefitted more from the COMB intervention for fat mass than healthy/overweight patients.

Menopausal status moderated the effect of the exercise interventions on bodily pain ( $P$ for interaction $=0.015$; Figure $2 \mathrm{a}$ ), endocrine symptoms ( $P$ for interaction $=0.039$; Figure $2 b$ ), and taxane/neuropathy symptoms $(P$ for interaction $=0.016$; Figure $2 \mathrm{c}$ ). Age moderated the effect of the exercise interventions on bodily pain $(P$ for interaction $=0.023$; Figure $2 \mathrm{~d}$ ) and taxane/neuropathy symptoms $(P$ for interaction $=0.045$; Figure $2 \mathrm{e}$ ). Stratified subgroup analyses (Table 3 ) generally showed that premenopausal and younger patients responded better to the HIGH intervention compared with postmenopausal and older patients. Finally, baseline aerobic fitness moderated the effect of the exercise interventions on endocrine symptoms $(P$ for interaction $=0.001$; Figure $2 \mathrm{f}$ ) and taxane/ neuropathy symptoms ( $P$ for interaction $=0.041$; Figure $2 \mathrm{~g}$ ). Stratified subgroup analyses (Table 3 ) showed that fitter patients benefited more from both the higher-dose exercise interventions, whereas less fit patients showed no benefit.

No significant interactions were observed for the moderators of marital status, disease stage, type of surgery, anthracycline treatment, taxane treatment, length of chemotherapy, or meeting either exercise guideline at baseline. Moreover, no significant interactions were observed for the outcomes of patient-reported physical functioning, fatigue, or lean body mass.

\section{DISCUSSION}

To our knowledge, the CARE Trial is the largest exercise trial to date to examine moderators of the exercise response in cancer patients, and the first to examine moderators of different types and doses of exercise. The most consistent moderator of the exercise response in the CARE Trial was body mass index. As hypothesised, the general pattern of findings was that healthy weight patients experienced greater benefit from the higher-dose interventions than overweight/ obese patients. In the Healthy Exercise for Lymphoma Patients (HELP) Trial, we observed that healthy weight and obese (but not overweight) patients achieved a better response to aerobic exercise for patient-reported physical functioning (Courneya et al, 2009) and that obese patients achieved a better response for sleep quality (Courneya et al, 2012). Conversely, a study of endometrial cancer survivors reported no differences in response to an unsupervised exercise programme based on body mass index; however, that study did not have a comparison group (Basen-Engquist et al, 2014). One possible explanation for our finding is that the overweight/obese patients had worse adherence to the higher-dose exercise interventions (about $65 \%$ ) compared with the standard dose intervention (about 80\%) (Courneya et al, 2014b). Another possible explanation is that the additional symptom burden experienced by obese breast cancer patients may blunt the response to the higher-dose exercise interventions (Schmitz et al, 2013). 


\begin{tabular}{|c|c|c|c|c|c|c|}
\hline & \multicolumn{2}{|c|}{ HIGH vs STAN } & \multicolumn{2}{|c|}{ COMB vs STAN } & \multicolumn{2}{|c|}{ HIGH vs COMB } \\
\hline & $\mathrm{M}(95 \% \mathrm{Cl})$ & $P$ & $\mathrm{M}(95 \% \mathrm{Cl})$ & $P$ & $\mathrm{M}(95 \% \mathrm{Cl})$ & $P$ \\
\hline \multicolumn{7}{|l|}{ Bodily pain } \\
\hline $\begin{array}{l}\text { Healthy weight }(n=146) \\
\text { Overweight/obese }(n=150)\end{array}$ & $\begin{array}{l}+3.6(+1.0 \text { to }+6.1) \\
+0.2(-2.7 \text { to }+3.1)\end{array}$ & $\begin{array}{c}0.006 \\
0.88\end{array}$ & $\begin{array}{l}+2.6(-0.1 \text { to }+5.3) \\
-2.1(-4.7 \text { to }+0.6)\end{array}$ & $\begin{array}{c}0.059 \\
0.12\end{array}$ & $\begin{array}{l}+1.0(-1.5 \text { to }+3.5) \\
+2.3(-0.4 \text { to }+5.0)\end{array}$ & $\begin{array}{c}0.44 \\
0.097\end{array}$ \\
\hline \multicolumn{7}{|l|}{ Endocrine symptoms } \\
\hline $\begin{array}{l}\text { Healthy weight }(n=146) \\
\text { Overweight/obese }(n=150)\end{array}$ & $\begin{array}{l}+4.2(+1.7 \text { to }+6.7) \\
-0.4(-3.5 \text { to }+2.8)\end{array}$ & $\begin{array}{c}0.001 \\
0.81\end{array}$ & $\begin{array}{l}+5.5(-0.1 \text { to }+5.3) \\
+0.3(-2.5 \text { to }+3.2)\end{array}$ & $\begin{array}{c}<0.001 \\
0.82\end{array}$ & $\begin{array}{l}-1.3(-3.8 \text { to }+1.2) \\
-0.7(-3.6 \text { to }+2.2)\end{array}$ & $\begin{array}{l}0.32 \\
0.63\end{array}$ \\
\hline \multicolumn{7}{|l|}{ Taxane symptoms } \\
\hline $\begin{array}{l}\text { Healthy weight }(n=146) \\
\text { Overweight/obese }(n=150)\end{array}$ & $\begin{array}{l}+3.8(+1.6 \text { to }+5.9) \\
-2.1(-5.3 \text { to }+1.0)\end{array}$ & $\begin{array}{c}0.001 \\
0.18\end{array}$ & $\begin{array}{l}+1.7(-0.6 \text { to }+4.1) \\
-1.0(-3.9 \text { to }+1.9)\end{array}$ & $\begin{array}{l}0.14 \\
0.48\end{array}$ & $\begin{array}{l}+2.0(-0.2 \text { to }+4.2) \\
-1.1(-4.1 \text { to }+1.9)\end{array}$ & $\begin{array}{c}0.069 \\
0.46\end{array}$ \\
\hline \multicolumn{7}{|c|}{ Aerobic fitness $\left(\mathrm{ml} \mathrm{kg}^{-1} \mathrm{~min}^{-1}\right)$} \\
\hline $\begin{array}{l}\text { Healthy weight }(n=143) \\
\text { Overweight/obese }(n=135)\end{array}$ & $\begin{array}{l}+1.7(+0.1 \text { to }+3.2) \\
-0.4(-1.7 \text { to }+0.9)\end{array}$ & $\begin{array}{c}0.032 \\
0.56\end{array}$ & $\begin{array}{l}+1.0(-0.7 \text { to }+2.7) \\
-1.3(-2.5 \text { to }-0.2)\end{array}$ & $\begin{array}{l}0.26 \\
0.026\end{array}$ & $\begin{array}{l}+0.7(-0.9 \text { to }+2.3) \\
+1.0(-0.3 \text { to }+2.2)\end{array}$ & $\begin{array}{l}0.38 \\
0.12\end{array}$ \\
\hline \multicolumn{7}{|l|}{ Muscular strength $(\mathrm{kg})$} \\
\hline $\begin{array}{l}\text { Healthy weight }(n=143) \\
\text { Overweight/obese }(n=135)\end{array}$ & $\begin{array}{l}-2.5(-4.4 \text { to }-0.6) \\
-0.3(-2.7 \text { to }+3.1)\end{array}$ & $\begin{array}{c}0.010 \\
0.80\end{array}$ & $\begin{array}{l}+5.3(+3.2 \text { to }+7.4) \\
+2.8(+0.7 \text { to }+4.9)\end{array}$ & $\begin{array}{l}<0.001 \\
0.008\end{array}$ & $\begin{array}{l}-7.8(-9.7 \text { to }-5.9) \\
-3.1(-5.3 \text { to }-0.9)\end{array}$ & $\begin{array}{l}<0.001 \\
0.006\end{array}$ \\
\hline \multicolumn{7}{|l|}{ Fat mass $(\mathrm{kg})$} \\
\hline $\begin{array}{l}\text { Healthy/overweight }(n=223) \\
\text { Obese }(n=66)\end{array}$ & $\begin{array}{l}-0.4(-1.2 \text { to }+0.4) \\
+1.3(-1.6 \text { to }+4.2)\end{array}$ & $\begin{array}{l}0.28 \\
0.38\end{array}$ & $\begin{array}{l}+0.2(-0.7 \text { to }+1.0) \\
-1.5(-4.0 \text { to }+1.0)\end{array}$ & $\begin{array}{l}0.70 \\
0.23\end{array}$ & $\begin{array}{l}-0.6(-1.4 \text { to }+0.2) \\
+2.8(+0.4 \text { to }+5.2)\end{array}$ & $\begin{array}{c}0.14 \\
0.024\end{array}$ \\
\hline
\end{tabular}

Obesity is a growing issue in cancer care with obese cancer patients experiencing more treatment complications and poorer outcomes than healthy weight patients (Schmitz et al, 2013). Our data suggest minimal benefit from higher-dose exercise interventions compared with a standard exercise dose for overweight/obese breast cancer patients receiving chemotherapy. Interestingly, the one benefit that favoured obese patients was fat loss from the COMB intervention. Previous trials have reported that combined exercise produces more fat loss than aerobic or resistance exercise alone even when controlling for exercise volume (Church et al, 2010; Ho et al, 2012). This fat loss from COMB in obese breast cancer patients receiving chemotherapy may have important implications for reducing recurrence and early mortality (Schmitz et al, 2013). Exercise type and dose trials specifically targeting body composition in obese breast cancer patients may be warranted.

Two of the other identified moderators, menopausal status and age, are closely linked. These variables moderated the exercise response for bodily pain, endocrine symptoms, and taxane/ neuropathy symptoms. Stratified subgroup analyses showed that premenopausal and younger patients responded to the HIGH intervention, whereas postmenopausal and older patients showed no additional benefits. Differences in adherence do not appear to explain these findings (Courneya et al, 2014b). In the Supervised Trial of Aerobic vs Resistance Training (START), we found that younger breast cancer patients receiving chemotherapy experienced a better aerobic fitness response than older patients (Courneya et al, 2008). Conversely, age did not predict the exercise response of prostate cancer patients receiving radiation therapy (Alberga et al, 2012). Age is associated with greater functional decline and more cancer treatment complications that may impede the ability to benefit from higher-dose exercise compared with standard doses (Courneya et al, 2004). It is also possible that premenopausal/younger breast cancer patients benefit more because they are forced into early menopause from the chemotherapy treatments and experience more symptoms (Loprinzi et al, 2008).

Interestingly, none of the 'cancer variables' moderated the effects of exercise on the main outcomes. We previously reported in the CARE Trial that the type of surgery moderated the effects of exercise on sleep quality (Courneya et al, 2014c) and that taxane treatment moderated the effects on depression (Courneya et al, 2014a). Moreover, in START, we found that taxane treatment moderated the effects of weight training on muscular strength gains; and disease stage moderated the effects on body composition changes (Courneya et al, 2008). Other studies have also reported that cancer variables moderate the exercise response of lymphoma patients (Courneya et al, 2009, 2012) and breast cancer patients (Segal et al, 2001) but not prostate cancer patients (Segal et al, 2003). It is possible that cancer variables moderate the effects of exercise interventions differently depending on the type of cancer, the types of treatments, and whether exercise is compared with no exercise or with different types and doses of exercise. Cancer variables should continue to be explored as moderators of the exercise response because they are fundamental to the field of exercise oncology (Courneya, 2014).

We also found no significant interactions for marital status despite reporting such interactions in two previous trials (Courneya et al, 2008, 2009). In the START (Courneya et al, 2008) and HELP Trials (Courneya et al, 2009), unmarried breast cancer and lymphoma patients experienced a greater quality of life benefit than married patients from a supervised exercise programme compared 
A

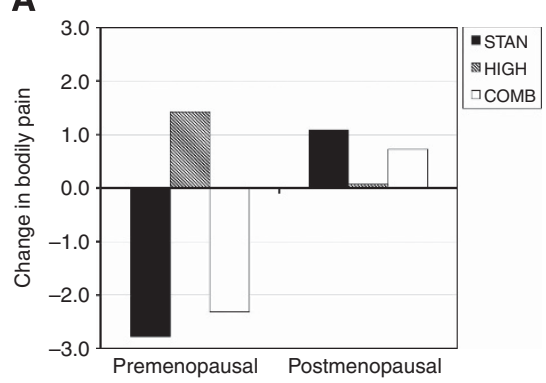

C

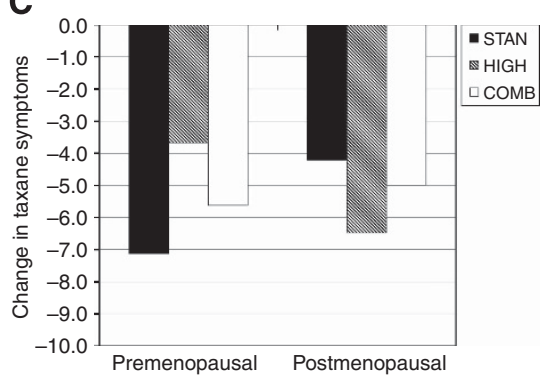

E

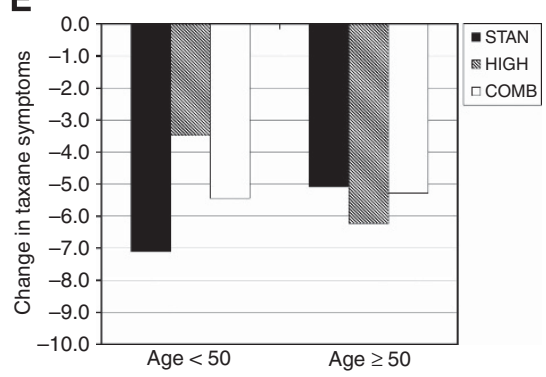

G

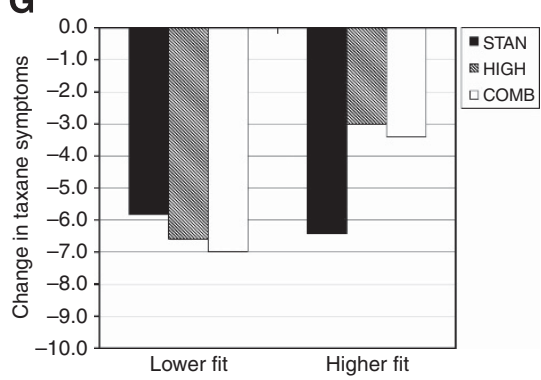

B

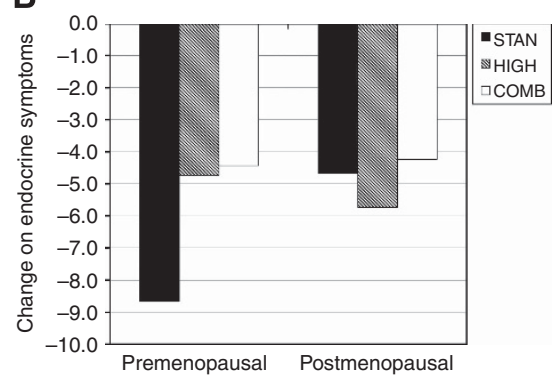

D

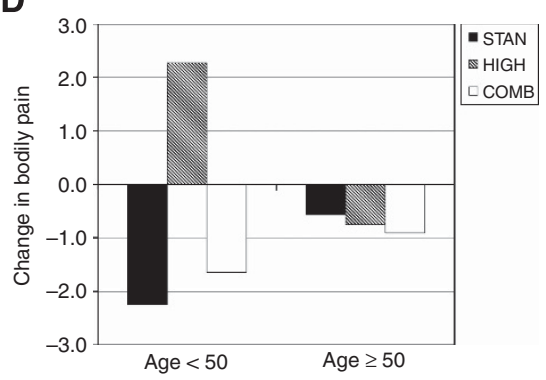

F

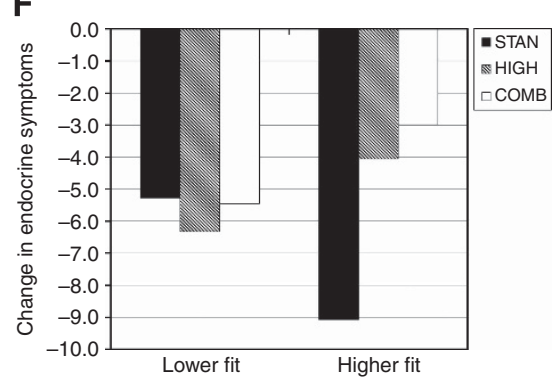

Figure 2. Menopausal status as a moderator of exercise effects during breast cancer chemotherapy on (A) bodily pain, (B) endocrine symptoms, and (C) taxane symptoms; age as a moderator of exercise effects during breast cancer chemotherapy on (D) bodily pain and (E) taxane symptoms; and baseline aerobic fitness as a moderator of exercise effects during breast cancer chemotherapy on (F) endocrine symptoms and (G) taxane symptoms. Note: positive change scores (or less negative change scores) are better for all outcomes. Abbreviations:

$\mathrm{COMB}=$ combined aerobic and resistance exercise; $\mathrm{HIGH}=$ high volume of aerobic exercise; STAN = standard volume of aerobic exercise.

with no exercise. In the CARE Trial, all three groups received a supervised exercise intervention with similar social interaction and support, thereby negating any social support benefit from a supervised exercise intervention. Again, these data suggest that moderators of the exercise response may vary when comparing exercise to no exercise $v s$ different types and doses of exercise.

We also found no significant interactions involving self-reported baseline exercise. This finding is interesting because self-reported exercise is often used as an exclusion criterion with the assumption that cancer patients already meeting guidelines are less likely to benefit from an exercise intervention. Few trials, however, have actually tested this assumption. In fact, in previous reports from the CARE Trial, we actually observed that patients meeting the aerobic exercise guidelines were more likely to benefit from the HIGH intervention in terms of sleep quality (Courneya et al, 2014c), and patients meeting the strength exercise guidelines were more likely to benefit from the COMB intervention in terms of sleep quality (Courneya et al, 2014c) and depression (Courneya et al, 2014a). These data suggest that the effects of self-reported baseline exercise on the exercise response of cancer patients receiving chemotherapy may be complex and should be examined in future trials.

The overall strengths of our trial have been noted elsewhere (Courneya et al, 2013) and include being the largest exercise trial in breast cancer patients receiving chemotherapy, the first to compare exercise dose and type effects, multicentre recruitment, good adherence rates, intention-to-treat analysis, and trivial loss-to- 
Table 3. Stratified subgroup analyses for significant interactions based on menopausal status, age, and baseline aerobic fitness

\begin{tabular}{|c|c|c|c|c|c|c|}
\hline & \multicolumn{2}{|c|}{ HIGH vs STAN } & \multicolumn{2}{|c|}{ COMB vs STAN } & \multicolumn{2}{|c|}{ HIGH vs COMB } \\
\hline & M (95\% Cl) & $P$ & M $(95 \% \mathrm{Cl})$ & $P$ & $\mathrm{M}(95 \% \mathrm{Cl})$ & $P$ \\
\hline \multicolumn{7}{|l|}{ Bodily pain by menopause } \\
\hline $\begin{array}{l}\text { Premenopausal }(n=182) \\
\text { Postmenopausal }(n=114)\end{array}$ & $\begin{array}{l}+3.9(+1.7 \text { to }+6.2) \\
-0.6(-3.9 \text { to }+2.7)\end{array}$ & $\begin{array}{l}0.001 \\
0.72\end{array}$ & $\begin{array}{l}+0.3(-2.0 \text { to }+2.7) \\
-0.3(-3.2 \text { to }+2.7)\end{array}$ & $\begin{array}{l}0.78 \\
0.85\end{array}$ & $\begin{array}{l}+3.6(+1.2 \text { to }+6.0) \\
-0.3(-3.2 \text { to }+2.5)\end{array}$ & $\begin{array}{c}0.003 \\
0.82\end{array}$ \\
\hline \multicolumn{7}{|c|}{ Endocrine symptoms by menopause } \\
\hline $\begin{array}{l}\text { Premenopausal }(n=182) \\
\text { Postmenopausal }(n=114)\end{array}$ & $\begin{array}{l}+3.8(+1.2 \text { to }+6.4) \\
-0.2(-3.1 \text { to }+2.6)\end{array}$ & $\begin{array}{c}0.004 \\
0.87\end{array}$ & $\begin{array}{l}+4.3(+1.5 \text { to }+7.0) \\
+0.8(-1.8 \text { to }+3.4)\end{array}$ & $\begin{array}{c}0.003 \\
0.54\end{array}$ & $\begin{array}{l}-0.5(+1.2 \text { to }+6.0) \\
-1.0(-3.5 \text { to }+1.5)\end{array}$ & $\begin{array}{l}0.74 \\
0.42\end{array}$ \\
\hline \multicolumn{7}{|c|}{ Taxane symptoms by menopause } \\
\hline $\begin{array}{l}\text { Premenopausal }(n=182) \\
\text { Postmenopausal }(n=114)\end{array}$ & $\begin{array}{l}+3.0(+0.8 \text { to }+5.3) \\
-1.5(-4.9 \text { to }+1.8)\end{array}$ & $\begin{array}{l}0.008 \\
0.37\end{array}$ & $\begin{array}{l}+1.5(-0.8 \text { to }+3.9) \\
-0.8(-3.8 \text { to }+2.2)\end{array}$ & $\begin{array}{l}0.20 \\
0.60\end{array}$ & $\begin{array}{l}+1.5(-0.9 \text { to }+3.9) \\
-0.7(-3.7 \text { to }+2.2)\end{array}$ & $\begin{array}{l}0.21 \\
0.62\end{array}$ \\
\hline \multicolumn{7}{|l|}{ Bodily pain by age } \\
\hline $\begin{array}{l}<50 \text { years }(n=148) \\
\geqslant 50 \text { years }(n=148)\end{array}$ & $\begin{array}{l}+4.4(+2.0 \text { to }+6.9) \\
-0.0(-3.0 \text { to }+2.9)\end{array}$ & $\begin{array}{c}<0.001 \\
0.98\end{array}$ & $\begin{array}{l}+0.5(-2.2 \text { to }+3.1) \\
-0.0(-2.6 \text { to }+2.6)\end{array}$ & $\begin{array}{l}0.72 \\
0.99\end{array}$ & $\begin{array}{l}+4.0(+1.4 \text { to }+6.6) \\
-0.0(-2.7 \text { to }+2.6)\end{array}$ & $\begin{array}{l}0.003 \\
0.98\end{array}$ \\
\hline \multicolumn{7}{|l|}{ Taxane symptoms by age } \\
\hline $\begin{array}{l}<50 \text { years }(n=148) \\
\geqslant 50 \text { years }(n=148)\end{array}$ & $\begin{array}{l}+3.4(+1.0 \text { to }+5.7) \\
-0.4(-3.4 \text { to }+2.6)\end{array}$ & $\begin{array}{c}0.005 \\
0.80\end{array}$ & $\begin{array}{l}+1.8(-0.7 \text { to }+4.4) \\
-0.2(-2.9 \text { to }+2.5)\end{array}$ & $\begin{array}{l}0.16 \\
0.88\end{array}$ & $\begin{array}{l}+1.6(-1.0 \text { to }+4.1) \\
-0.2(-2.9 \text { to }+2.5)\end{array}$ & $\begin{array}{l}0.22 \\
0.90\end{array}$ \\
\hline \multicolumn{7}{|c|}{ Endocrine symptoms by aerobic fitness } \\
\hline $\begin{array}{l}<27.5 \mathrm{mlkg}^{-1} \min ^{-1}(n=145) \\
\geqslant 27.5 \mathrm{ml} \mathrm{kg}^{-1} \min ^{-1}(n=151)\end{array}$ & $\begin{array}{l}-1.1(-3.9 \text { to }+1.7) \\
+5.3(+2.6 \text { to }+8.0)\end{array}$ & $\begin{array}{c}0.44 \\
<0.001\end{array}$ & $\begin{array}{l}-0.2(-2.9 \text { to }+2.4) \\
+5.9(+3.1 \text { to }+8.8)\end{array}$ & $\begin{array}{c}0.86 \\
<0.001\end{array}$ & $\begin{array}{l}-0.9(-3.5 \text { to }+1.8) \\
-0.6(-3.4 \text { to }+2.1)\end{array}$ & $\begin{array}{l}0.51 \\
0.65\end{array}$ \\
\hline \multicolumn{7}{|c|}{ Taxane symptoms by aerobic fitness } \\
\hline $\begin{array}{l}<27.5 \mathrm{ml} \mathrm{kg}^{-1} \min ^{-1}(n=145) \\
\geqslant 27.5 \mathrm{mlkg}^{-1} \min ^{-1}(n=151)\end{array}$ & $\begin{array}{l}-0.7(-3.8 \text { to }+2.4) \\
+3.1(+1.0 \text { to }+5.3)\end{array}$ & $\begin{array}{c}0.65 \\
0.005\end{array}$ & $\begin{array}{l}-1.3(-4.2 \text { to }+1.7) \\
+3.1(+0.7 \text { to }+5.4)\end{array}$ & $\begin{array}{c}0.39 \\
0.010\end{array}$ & $\begin{array}{l}+0.6(-2.4 \text { to }+3.5) \\
+0.1(-2.2 \text { to }+2.3)\end{array}$ & $\begin{array}{l}0.70 \\
0.95\end{array}$ \\
\hline
\end{tabular}

follow-up. Additional strengths of the present report include the clinical utility of our selected moderators, our inclusion of several novel cancer variables as moderators, and the direct tests of interactions. The overall limitations of our trial have also been noted elsewhere (Courneya et al, 2013) and include the modest recruitment rate and the lower adherence rates among the higherdose exercise groups. Additional limitations of the present report include our limited statistical power to detect interactions and the 96 interaction tests that would likely result in 5 false discoveries if all tests were null. Nevertheless, the 13 significant interactions we identified showed a consistent pattern of moderators (i.e., body mass index, age, menopausal status, and fitness) and outcomes (i.e., bodily pain, endocrine symptoms, and taxane/neuropathy symptoms) that suggest a low likelihood of chance findings.

It is also important to note that the CARE Trial manipulated only one component of exercise dose and tested only one approach for combining aerobic and resistance exercise. In the CARE Trial, the HIGH group performed double the duration of a vigorous intensity aerobic exercise intervention that was performed 3 days per week. We did not manipulate the intensity, frequency, or periodisation of aerobic exercise and, therefore, cannot speak to the effects or subgroup effects of such manipulations in breast cancer patients receiving chemotherapy. Moreover, the COMB group performed the resistance exercise immediately after the aerobic exercise and, therefore, we cannot speak to the effects or subgroup effects of a combined exercise programme where the aerobic and resistance exercise are performed on separate days or where the resistance exercise is performed before the aerobic exercise.
In summary, our moderator analyses of the main outcomes of the CARE Trial showed a general pattern in which slimmer, fitter, and younger/premenopausal breast cancer patients receiving chemotherapy were more likely to benefit from the higher-dose exercise interventions than their counterparts. These results reinforce the idea that exercise prescriptions in cancer patients should be individualised, taking into account age, menopausal status, obesity, past exercise experience, initial fitness level, and treatment protocol. In terms of dissemination, these higher-dose exercise interventions could be implemented at other cancer centres and community-based fitness centres with appropriate facilities and qualified staff. Given their level of sophistication and required motivation, it is unclear whether these exercise programmes could be self-directed by breast cancer patients receiving chemotherapy. Additional research manipulating other aspects of the exercise prescription including frequency, intensity, periodisation, and sequencing are needed to determine the optimal exercise programme for breast cancer patients receiving chemotherapy. Moreover, identifying which cancer patients respond best to which type, volume, intensity, and sequencing of exercise interventions will further inform clinical practice and improve outcomes for breast cancer patients.

\section{ACKNOWLEDGEMENTS}

This work was supported by the Canadian Breast Cancer Research Alliance (\#91807). KSC and YY are supported by the Canada 
Research Chairs Program. CMF and YY are supported by Health Senior Scholar Awards from Alberta Innovates-Health Solutions. CMF is supported by the Alberta Cancer Foundation's Weekend to End Women's Cancers Breast Cancer Chair.

\section{CONFLICT OF INTEREST}

The authors declare no conflict of interest.

\section{REFERENCES}

Alberga AS, Segal RJ, Reid RD, Scott CG, Sigal RJ, Khandwala F, Jaffey J, Wells GA, Kenny GP (2012) Age and androgen-deprivation therapy on exercise outcomes in men with prostate cancer. Support Care Cancer 20(5): 971-981.

Basen-Engquist K, Carmack C, Brown J, Jhingran A, Baum G, Song J, Scruggs S, Swartz MC, Cox MG, Lu KH (2014) Response to an exercise intervention after endometrial cancer: differences between obese and nonobese survivors. Gynecol Oncol 133(1): 48-55.

Cella D, Peterman A, Hudgens S, Webster K, Socinski MA (2003) Measuring the side effects of taxane therapy in oncology: the functional assesment of cancer therapy-taxane (FACT-taxane). Cancer 98(4): 822-831.

Church TS, Blair SN, Cocreham S, Johannsen N, Johnson W, Kramer K, Mikus CR, Myers V, Nauta M, Rodarte RQ, Sparks L, Thompson A, Earnest CP (2010) Effects of aerobic and resistance training on hemoglobin A1c levels in patients with type 2 diabetes: a randomized controlled trial. JAMA 304(20): 2253-2262.

Courneya KS (2014) Physical activity and cancer survivorship: a simple framework for a complex field. Exerc Sport Sci Rev 42(3): 102-109.

Courneya KS, McKenzie DC, Gelmon K, Mackey JR, Reid RD, Yasui Y, Friedenreich CM, Forbes CC, Trinh L, Jespersen D, Cook D, Proulx C, Wooding E, Dolan LB, Segal RJ (2014a) A multicenter randomized trial of the effects of exercise dose and type on psychosocial distress in breast cancer patients undergoing chemotherapy. Cancer Epidemiol Biomarkers Prev 23(5): 857-864.

Courneya KS, McKenzie DC, Mackey JR, Gelmon K, Friedenreich CM, Yasui Y, Reid RD, Cook D, Jespersen D, Proulx C, Dolan LB, Forbes CC, Wooding E, Trinh L, Segal RJ (2013) Effects of exercise dose and type during breast cancer chemotherapy: multicenter randomized trial. J Natl Cancer Inst 105(23): 1821-1832.

Courneya KS, McKenzie DC, Mackey JR, Gelmon K, Reid RD, Friedenreich CM, Ladha AB, Proulx C, Vallance JK, Lane K, Yasui Y, Segal RJ (2008) Moderators of the effects of exercise training in breast cancer patients receiving chemotherapy: a randomized controlled trial. Cancer 112(8): 1845-1853.

Courneya KS, Segal RJ, Gelmon K, Mackey JR, Friedenreich CM, Yasui Y, Reid RD, Proulx C, Trinh L, Dolan LB, Wooding E, Vallerand JR, McKenzie DC (2014b) Predictors of adherence to different types and doses of supervised exercise during breast cancer chemotherapy. Int J Behav Nutr Phys Act 11(1): 85.

Courneya KS, Segal RJ, Mackey JR, Gelmon K, Friedenreich CM, Yasui Y, Reid RD, Jespersen D, Cook D, Proulx C, Trinh L, Dolan LB, Wooding E, Forbes CC, McKenzie DC (2014c) Effects of exercise dose and type on sleep quality in breast cancer patients receiving chemotherapy: a multicenter randomized trial. Breast Cancer Res Treat 144(2): 361-369.

Courneya KS, Sellar CM, Stevinson C, McNeely ML, Friedenreich CM, Peddle CJ, Basi S, Chua N, Tankel K, Mazurek A, Reiman T (2009) Moderator effects in a randomized controlled trial of exercise training in lymphoma patients. Cancer Epidemiol Biomarkers Prev 18(10): 2600-2607.

Courneya KS, Sellar CM, Trinh L, Forbes CC, Stevinson C, McNeely ML, Peddle-McIntyre CJ, Friedenreich CM, Reiman T (2012) A randomized trial of aerobic exercise and sleep quality in lymphoma patients receiving chemotherapy or no treatments. Cancer Epidemiol Biomarkers Prev 21(6): 887-894.
Courneya KS, Vallance JK, McNeely ML, Karvinen KH, Peddle CJ, Mackey JR (2004) Exercise issues in older cancer survivors. Crit Rev Oncol Hematol 51(3): 249-261.

Diggle P, Heagerty P, Liang K, Zeger SL (2002) Analysis of Longitudinal Data. Oxford University Press: New York, NY, USA.

Fallowfield LJ, Leaity SK, Howell A, Benson S, Cella D (1999) Assessment of quality of life in women undergoing hormonal therapy for breast cancer: validation of an endocrine symptom subscale for the FACT-B. Breast Cancer Res Treat 55(2): 189-199.

Ho SS, Dhaliwal SS, Hills AP, Pal S (2012) The effect of 12 weeks of aerobic, resistance or combination exercise training on cardiovascular risk factors in the overweight and obese in a randomized trial. BMC Public Health 12: 704.

Kraemer WJ, Adams K, Cafarelli E, Dudley GA, Dooly C, Feigenbaum MS, Fleck SJ, Franklin B, Fry AC, Hoffman JR, Newton RU, Potteiger J, Stone MH, Ratamess NA, Triplett-McBride T. American College of Sports M (2002) American College of Sports Medicine position stand. Progression models in resistance training for healthy adults. Med Sci Sports Exerc 34(2): 364-380.

Loprinzi CL, Wolf SL, Barton DL, Laack NN (2008) Symptom management in premenopausal patients with breast cancer. Lancet Oncol 9(10): 993-1001.

Mishra SI, Scherer RW, Geigle PM, Berlanstein DR, Topaloglu O, Gotay CC, Snyder C (2012a) Exercise interventions on health-related quality of life for cancer survivors. Cochrane Database Syst Rev 8: CD007566.

Mishra SI, Scherer RW, Snyder C, Geigle PM, Berlanstein DR, O T (2012b) Exercise interventions on health-related quality of life for people with cancer during active treatment. Cochrane Database Syst Rev 15: CD008465.

Rock CL, Doyle C, Demark-Wahnefried W, Meyerhardt J, Courneya KS, Schwartz AL, Bandera EV, Hamilton KK, Grant B, McCullough M, Byers T, Gansler T (2012) Nutrition and physical activity guidelines for cancer survivors. CA Cancer J Clin 62(4): 243-274.

Schmitz KH, Courneya KS, Matthews C, Demark-Wahnefried W, Galvao DA, Pinto BM, Irwin ML, Wolin KY, Segal RJ, Lucia A, Schneider CM, von Gruenigen VE, Schwartz AL. American College of Sports M (2010) American College of Sports Medicine roundtable on exercise guidelines for cancer survivors. Med Sci Sports Exerc 42(7): 1409-1426.

Schmitz KH, Neuhouser ML, Agurs-Collins T, Zanetti KA, Cadmus-Bertram L, Dean LT, Drake BF (2013) Impact of obesity on cancer survivorship and the potential relevance of race and ethnicity. J Natl Cancer Inst 105(18): 1344-1354.

Segal R, Evans W, Johnson D, Smith J, Colletta S, Gayton J, Woodard S, Wells G, Reid R (2001) Structured exercise improves physical functioning in women with stages I and II breast cancer: results of a randomized controlled trial. J Clin Oncol 19(3): 657-665.

Segal RJ, Reid RD, Courneya KS, Malone SC, Parliament MB, Scott CG, Venner PM, Quinney HA, Jones LW, D’Angelo ME, Wells GA (2003) Resistance exercise in men receiving androgen deprivation therapy for prostate cancer. J Clin Oncol 21(9): 1653-1659.

United States Department of Health and Human Services (2008) 2008 Physical Activity Guidelines for Americans, accessed 12 October 2013 http://www.health.gov/PAGuidelines.

Ware Jr. JE, Kosinski M, Bayliss MS, McHorney CA, Rogers WH, Raczek A (1995) Comparison of methods for the scoring and statistical analysis of SF-36 health profile and summary measures: summary of results from the Medical Outcomes Study. Med Care 33(4 Suppl): AS264-AS279.

Wasserman K, Hansen J, Sue D, Casburi R, Whipp B (1999) Principles of Exercise Testing and Intepretation. 3 edn (Lippincott Williams \& Williams: Baltimore, MD, USA

Yellen SB, Cella DF, Webster K, Blendowski C, Kaplan E (1997) Measuring fatigue and other anemia-related symptoms with the Functional Assessment of Cancer Therapy (FACT) measurement system. J Pain Symptom Manage 13(2): 63-74.

This work is published under the standard license to publish agreement. After 12 months the work will become freely available and the license terms will switch to a Creative Commons AttributionNonCommercial-Share Alike 3.0 Unported License. 